\title{
Prevalence of Ceftriaxon-Sensitive Pneumococci Infection and Use of E- Test for Patients Admitted to Ghaem and Imam Reza Hospitals During a Two-Year Period
}

\author{
Ashraf Tavanaee Sani ${ }^{1,}$, , Maryam Mojtabavi ${ }^{1}$, Kiarash Ghazvini $^{2}$ \\ 1 Department of Infectious Diseases, Imam Reza Hospital, Mashhad University of Medical Sciences, Mashhad, IR Iran \\ 2 Department of Microbiology, Ghaem Hospital, Mashhad University of Medical Sciences, Mashhad, IR Iran \\ *Corresponding author: Ashraf Tavanaee Sani, Department of Infectious Diseases, Imam Reza Hospital, Mashhad University of Medical Sciences, Mashhad, IR Iran. Tel.: +98- \\ 9155091439,+98-5118515001, Fax:+98-5118591057, E-mail: tavanaeea@mums.ac.ir.
}

Received: April 06, 2012; Revised: April 20, 2012; Accepted: May 03, 2012

\begin{abstract}
Background: The emergence of Penicillin resistance and multidrug-resistant pneumococcal strains is a global concern. Several reports have demonstrated a correlation between increased Minimal Inhibitory Concentration (MIC) of Penicillin, and increased MICs of Cephalosporins and other $\beta$-lactam antibiotics. It should be pointed out that pneumococcal resistance to Penicillin may predict an unfavorable response to other $\beta$-lactam antibiotics.

Objectives:To outline pneumococcal resistance to Ceftriaxone, a microbiological survey was performed on pneumococcal strains, during a two-year period.

Patients and Methods: In this study, 35 strains of Pneumococci were isolated from blood samples of 35 different consecutive patients, admitted to two educational hospitals in Mashhad, North East of Iran during a two-year period of this prospective study, the minimal inhibitory concentration (MIC) of Ceftriaxone was determined, using E-test.

Results: Amongst 35 clinical isolates, evaluated in this study, only one isolate (2.86\%) was resistant to Ceftriaxone (MIC $>1$ ) and 34 isolates (97.14\%)appeared to be sensitive to this antibiotic. MIC ranged from 0.012 to 6 and MIC50 and MIC90 were 0.07 and 0.5 , respectively.

Conclusions: Considering the low rate of Ceftriaxone resistance amongst isolated pneumcocci.in this study, Only Ceftriaxone treatment of adult patients with invasive pneumococcal infections (other than CNS infections) is sufficient; but pediatric patients and patients with CNS infections should be treated with Ceftriaxone and Vancomycin. Apparently, diminution of Vancomycin use can be resulted in reduction of the resistance rate among other bacteria, sensitive to this antimicrobial agent, such as Methicillin-resistant Staphylococcus aureus and Enterococci.
\end{abstract}

Keywords: Ceftriaxone; Pneumococci; Sensitivity and Specificity

\section{Background}

Streptococcus Pneumonia is the major cause of community-acquired pneumonia and meningitis (1) which may affect patients in all age groups, particularly those underlying medical conditions (1). The emergence of Penicillin resistance and multidrug-resistant in pneumococcal strains has become a global concern. Since late 1980s, antibiotic-resistant Pneumococci sp. has been markedly increased worldwide and is recognized as globally spread pathogens (2). Traditionally, laboratories screened clinically significant isolates of $S$. Pneumonia to evaluate the Penicillin resistance with a 1-mg oxacillin disk (3). Several reports have demonstrated a correlation between increased MICs of Penicillin and increased MICs of Cephalosporins and other $\beta$-lactam antibiotics (4-6), showing that pneumococcal resistance to Penicillin may predict an unfavorable response to other antibiotics (2).

Penicillin-resistant Pneumococci is particularly common in Europe, South Africa, Latin America and United States (7-9), and the prevalence have been increased through the time. For instance, in the United States, resistance to Penicillin was 5\% before 1989 (including $0.02 \%$ of isolates for which MICs were $2.0 \mathrm{mg} / \mathrm{mL}$ ). However, this amount was 6.6\% in 1991-1992, 9.5\% in 1994-1995, 21.5\% in 1999-2000, and decreased to $14.6 \%$ in 2004-2005, after introduction of heptavalent pneumococcal conjugate vaccine (10-12). Resistant Pneumococci may spread from one country to another hence widened and intensified surveillance is needed in all areas, especially in countries where resistance is relatively uncommon $(13,14)$. Given the significant rate of Penicillin resistance, broad spectrum Cephalosporins (especially Ceftriaxone) are the proper choices for pneumococcal infections (15-17). All in all, there are studies reporting the increase in Ceftriaxone resistance among pneumococcal isolates (18-20), it is important to monitor the changing pattern and prevalence of antibiotic resistance in order to provide reliable information

Implication for health policy/practice/research/medical education:

The main message of this study is that whether Pneumococci are sensitive to Ceftriaxone or not.

Copyright (C) 2012, Shahid Beheshti University of Medical Sciencces;. This is an Open Access article distributed under the terms of the Creative Commons Attribution License (http://creativecommons.org/licenses/by/3.0), which permits unrestricted use, distribution, and reproduction in any medium, provided the original work is properly cited. 
to refer to in empirical treatments of clinical infections.

\section{Objectives}

To consider the Ceftriaxone pneumococcal resistance pattern, one of the most prescribed antimicrobial agents in our region, microbiological survey was performed on pneumococcal strains during a two-year period. This study investigated the in vitro activities of isolated organisms, using E-test.

\section{Patients and Methods}

In the present study, 35 strains of Pneumococci were isolated from blood samples of 35 different patients admitted to two educational hospitals in Mashhad, North East of Iran. Minimal inhibitory concentration to Ceftriaxone determined, using E-test method based on the manufacturer instructions. Interpretation of the results was carried out according to Clinical and Laboratory Standards Institute (CLSI) definitions (21). According to the CLSI definition for non-meningeal isolates, a microorganism is considered as a susceptible isolated if MIC $\leq 1 \mu \mathrm{g} / \mathrm{mL}$, intermediately resistant if $\mathrm{MIC}=2 \mu \mathrm{g} / \mathrm{mL}$, and resistant if MIC $\geq 4 \mu \mathrm{g} / \mathrm{mL}$.

\section{Results}

Amongst 35 clinical isolates evaluated in this study, based on CLSI guidelines, only one isolate $(2.86 \%)$ was resistant to Ceftriaxone (MIC > 1) and 34 isolates (97.14\%) were sensitive to this antibiotic (Figure 1).

Figure 1. Ceftriaxone MIC for Pneumococci

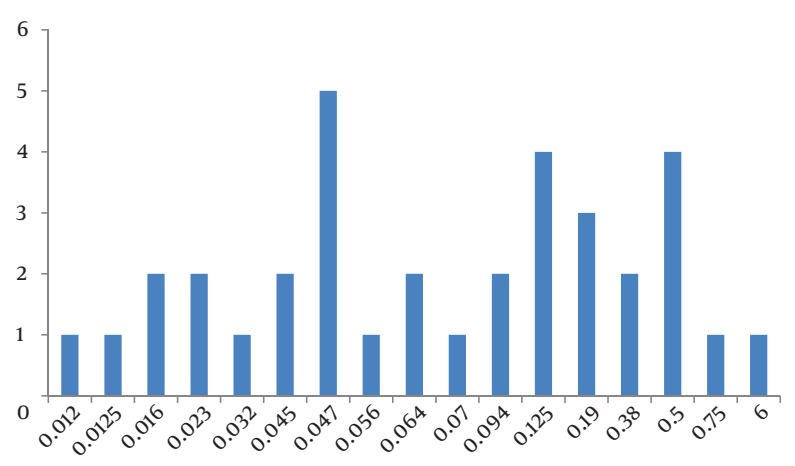

MIC ranged from 0.012 to 6 and MIC50 and MIC90 were 0.07 and 0.5, respectively.

\section{Discussion}

As reported in many studies, there is a high frequency of Penicillin resistance among pneumococcal isolates, but the resistance to Ceftriaxone is variable. There are some studies in which the trends of Ceftriaxone susceptibility have been evaluated. In a ten-year study $(1998$ - 2007) con- ducted in Calgary, Canada, 1.7\% of 1170 pneumococcal isolates were resistant to Ceftriaxone (22). Despite low level of resistance in previous study, in a retrospective study in a university hospital in Taiwan (2000 - 2007), 18.4\% of non-meningeal and $34.9 \%$ of meningeal isolates (a total number of 3729 isolates) were not susceptible to Ceftriaxone (23). Moreover, in a study conducted in Riyadh, Kingdom of Saudi Arabia, from February 2000 and November 2001, including 78 isolates of S. Pneumonia from different samples (blood, cerebrospinal fluid, bone, and peritoneal fluid) only $1.28 \%$ of isolates were resistant to Ceftriaxone (24) although authors suggested Ceftriaxone for treating invasive pneumococcal infections other than the central nervous system infections (25). A large study included 1,000 clinical isolates of $S$ pneumonia, collected by U.S. laboratories in 2001-2002 showed that nearly $2 \%$ of isolates were resistant to Ceftriaxone (26). The rate of resistance to Ceftriaxone in our study was similar to the other studies (2.86\%).

It is noticeable that studies on pediatric patients' samples, revealed higher rates of resistance, it showed that $35 \%$ of S. Pneumonia isolated from nasopharyngeal swabs of children from Darwin, Australia, and $24.7 \%$ of S. Pneumonia isolated from hypopharynx aspirate specimens collected from children admitted to 4 Children's hospital in Beijing, Shanghai and Guangzhou, China were resistant to Ceftriaxone $(27,28)$. Another study on 46 strains of S. Pneumonia isolated from children with different infections referred to an emergency ward of a pediatric hospital in Rumania, during January 2001 - September 2002, revealed $26.09 \%$ resistance to Ceftriaxone (29). In a study which was conducted in Isfahan, Iran 98 pneumococcal isolates obtained from pediatric patients aged $5-10$ years old, $89.1 \%$ and $81.5 \%$ of non-meningeal and meningeal isolates were susceptible to Ceftriaxone. MIC50 and MIC90 were 0.25 and 1.5, respectively; thus the authors suggested to administer Ceftriaxone in suspected cases of pneumococcal infection $(30,31)$.

Considering the low rates of Ceftriaxone resistance amongst isolated Pneumococci in this study, administering of Ceftriaxone alone for the treatment of adult patients with invasive pneumococcal infections (other than CNS infections) is effective; but pediatric patients and patients with CNS infections should be treated with Ceftriaxone and Vancomycin. It appears that the diminution in Vancomycin use has been resulted in decreased resistance rate of other bacteria which are sensitive to these antimicrobial agents (such as methicillin-resistant Staphylococcus aureus and Enterococci).

\section{Acknowledgements}

We would like to thank the Vice Chancellor for Research of Mashhad University of Medical Sciences for their financial support. 


\section{Authors' Contribution}

Study design, statistical analysis, drafting as well as supervision and critical revision of the manuscript for important intellectual concepts were carried out by Ashraf Tavanaee Sani. Collection in addition to the analysis and interpretation of the data were performed by Maryam Mojtabavi. Administrative and technical support was provided by Kiarash Ghazvini.

\section{Financial Disclosure}

The authors declare that there are no conflicts of interest.

\section{Funding/Support}

The study was funded by Vice Chancellor for Research of Mashhad University of Medical Sciences.

\section{References}

1. Musher DM. Streptococcus pneumoniae. In: Mandell L, Bennett JE, Dolin R, editors. Mandell, Douglas, and Bennett's principles and practice of infectious diseases. 7 ed. Philadelphia: Churchill Livingstone; 2010. p. 2635

2. Hoban DJ, Doern GV, Fluit AC, Roussel-Delvallez M, Jones RN. Worldwide prevalence of antimicrobial resistance in Streptococcus pneumoniae, Haemophilus influenzae, and Moraxella catarrhalis in the SENTRY Antimicrobial Surveillance Program, 1997-1999. Clin Infect Dis. 2001;32 Suppl 2:S81-93.

3. Swenson JM, Hill BC, Thornsberry C. Screening Pneumococci for Penicillin resistance. J Clin Microbiol.1986;24(5):749-52.

4. Jacobs MR, Koornhof HJ, Robins-Browne RM, Stevenson CM, Vermaak ZA, Freiman I, et al. Emergence of multiply resistant Pneumococci. N Engl J Med.1978;299(14):735-40.

5. Ward JI, Moellering RC, Jr. Susceptibility of Pneumococci to 14 beta-lactam agents: comparison of strains resistant, intermediate-resistant, and susceptible to penicillin. Antimicrob Agents Chemother:1981;20(2):204-7.

6. Li J, Zhang Y, Chen Y, Hao F. E test for studying in vitro activity of seven antimicrobial agents against Penicillin-susceptible and Penicillin-resistant Pneumococci. Chin Med J (Engl). 2000;113(7):628-31.

7. Linares J, Pallares R, Alonso T, Perez JL, Ayats J, Gudiol F, et al. Trends in antimicrobial resistance of clinical isolates of Streptococcus pneumoniae in Bellvitge Hospital, Barcelona, Spain (19791990). Clin Infect Dis. 1992;15(1):99-105.

8. Desa MNM, Lin TK, Yasin RMd, Parasakthi N. Penicillin susceptibility and molecular characteristics of clinical isolates of Streptococcus Pneumoniae at the University of Malaya Medical Center, Kuala Lumpur, Malaysia. Int J Infect Dis. 2003;7(3):190-197.

9. Johnson DM, Stilwell MG, Fritsche TR, Jones RN. Emergence of multidrug-resistant Streptococcus pneumoniae: report from the SENTRY Antimicrobial Surveillance Program (1999-2003). Diagn Microbiol Infect Dis. 2006;56(1):69-74.

10. Breiman RF, Butler JC, Tenover FC, Elliott JA, Facklam RR. Emergence of drug-resistant pneumococcal infections in the United States. JAMA. 1994;271(23):1831-5.

11. Doern GV, Heilmann KP, Huynh HK, Rhomberg PR, Coffman SL, Brueggemann AB. Antimicrobial resistance among clinical isolates of Streptococcus pneumoniae in the United States during 1999-2000, including a comparison of resistance rates since 1994-1995. Antimicrob Agents Chemother. 2001;45(6):1721-9.

12. Richter SS, Heilmann KP, Dohrn CL, Riahi F, Beekmann SE, Doern GV. Changing epidemiology of antimicrobial-resistant Streptococcus pneumoniae in the United States, 2004-2005. Clin Infect Dis. 2009;48(3):e23-33.

13. Doern GV. Susceptibility tests of fastidious bacteria. In: Murray
PR, Baron EJ, Pfaller MA, Tenover FC, Yolken RH, editors. Manual of clinical microbiology. 6 ed. Washington, D.C.: American Society for Microbiology; 1995. p. 1342-9.

14. Dowson CG, Johnson AP, Cercenado E, George RC. Genetics of oxacillin resistance in clinical isolates of Streptococcus pneumoniae that are oxacillin resistant and penicillin susceptible. Antimicrob Agents Chemother. 1994;38(1):49-53.

15. Aspa J, Rajas O, de Castro FR. Pneumococcal antimicrobial resistance: therapeutic strategy and management in community-acquired pneumonia. Expert Opin Pharmacother. 2008;9(2):229-41.

16. Van Bambeke F, Reinert RR, Appelbaum PC, Tulkens PM, Peetermans WE. Multidrug-resistant Streptococcus pneumoniae infections: current and future therapeutic options. Drugs. 2007;67(16):2355-82.

17. Chiou CC, Yu VL. Severe pneumococcal pneumonia: new strategies for management. Curr Opin Crit Care. 2006;12(5):470-6.

18. Chiu CH, Su LH, Huang YC, Lai JC, Chen HL, Wu TL, et al. Increasing ceftriaxone resistance and multiple alterations of penicillin-binding proteins among penicillin-resistant Streptococcus pneumoniae isolates in Taiwan. Antimicrob Agents Chemother. 2007;51(9):3404-6.

19. Song JH, Jung SI, Ko KS, Kim NY, Son JS, Chang HH, et al. High prevalence of antimicrobial resistance among clinical Streptococcus pneumoniae isolates in Asia (an ANSORP study). Antimicrob Agents Chemother. 2004;48(6):2101-7.

20. Hsu KK, Shea KM, Stevenson AE, Pelton SI. Changing serotypes causing childhood invasive pneumococcal disease: Massachusetts, 20 01-2007. Pediatr Infect Dis J. 2010;29(4):289-93.

21. Wayne PA. Performance standards for antimicrobial susceptibility testing, sixteenth informational supplement. Clin Lab Stand Inst. 2006;26(3).

22. Vanderkooi OG, McConnell A, Church DL, Kellner JD. Antimicrobial susceptibility of invasive and lower respiratory tract isolates of Streptococcus pneumoniae, 1998 to 2007. Can J Infect Dis Med Microbiol. 2009;20(4):e139-44.

23. Su LH, Wu TL, Kuo AJ, Chia JH, Chiu CH. Antimicrobial susceptibility of Streptococcus pneumoniae at a university hospital in Taiwan, 2000-07: impact of modified non-meningeal penicillin breakpoints in CLSI M100-S18. J Antimicrob Chemother. 2009;64(2):336-42.

24. Twum-Danso K, Al-Mazrou AM, Kambal AM, Al-Zamil FA. Penicillin resistance in serogroups/serotypes of Streptococcus pneumoniae causing invasive infections in Central Saudi Arabia. Saudi Med J. 2003;24(11):1210-3.

25. Mojtabavi M, Naderi HR, Tavanaee Sani A, Bagheri M, Ghazvini K. First Report of a Case of Pneumococcal Meningitis Which Did Not Respond to the Ceftriaxone Therapy despite the Isolated Organism Being Sensitive to This Antibiotic In Vitro. Case Rep Pulmonol. 2011;2011:485952.

26. Karlowsky JA, Jones ME, Draghi DC, Sahm DF. Clinical isolates of Streptococcus pneumoniae with different susceptibilities to ceftriaxone and cefotaxime. Antimicrob Agents Chemother 2003;47(10):3155-60.

27. Skull SA, Leach AJ, Currie BJ. Streptococcus pneumoniae carriage and penicillin/ceftriaxone resistance in hospitalised children in Darwin. Aust N Z J Med.1996;26(3):391-5.

28. Yao KH, Wang LB, Zhao GM, Zheng Y], Deng L, Zhao RZ, et al. [Surveillance of antibiotic resistance of Streptococcus pneumoniae isolated from hospitalized patients with pneumonia in four children's hospitals in China]. Zhongguo Dang Dai Er Ke Za Zhi. 2008;10(3):275-9.

29. Coman G, Petraru E, Filip R, Dahorea C, Butnaru F. Ceftriaxone resistance in Streptococcus Pneumoniae isolated from pediatric infections.J Prevent Med. 2002;10(4):49-55.

30. Mostafavizade K, Khourvash F, Abousaeidi H, Fasihi Dastjerdi M, Mobasherizadeh S, Izadi M, et al. Determination of Streptococcus pneumoniae resistant to penicillin and ceftriaxone by E-test method. Kowsar Medical J. 2008;12(4):325-30.

31. Varman M. Pediatric Pneumococcal Infections Medication. Med Scape; [cited September 8, 2011]; Available from: http://emedicine.medscape.com/article/967694-overview. 